\title{
A coordenação da administração pública federal brasileira em contextos de reformas administrativas
}

\author{
The coordination of the Brazilian federal public administration \\ in the context of administrative reforms
}

\author{
Raphael Amorim Machado \\ Doutorando em Ciência Política, bolsista CAPES, \\ Universidade Estadual de Campinas - UNICAMP \\ e-mail: raphaelmachado2@gmail.com
}

Recebido: 05/05/2013

Aceito: 01/07/2013
RESUmo Este artigo se propõe a discutir a coordenação da administração pública federal no momento de reformas administrativas, elencando para essa análise as três principais reformas do século XX, a saber: 1938, com a criação do DASP; 1967, com a instituição do Decreto-Lei 200 e a reforma de 1995 , já no período democrático. Partimos de duas hipóteses, a primeira é de que houve um padrão de continuidade na coordenação das três reformas administrativas estudadas, a segunda é que os órgãos centrais da coordenação administrativa estiveram fortemente atrelados ao Executivo federal. As reformas são tratadas como critical junctures, momentos nos quais há grande discricionariedade na formatação das instituições, favorecendo mudanças no tipo de coordenação, seja ela mais hierárquica (vertical) ou mais plural (horizontal). Foram analisadas as principais mudanças e dificuldades no padrão de coordenação da administração pública federal no Brasil nos períodos de reforma em tela.

PALAVRAS-ChaVe Coordenação; Reformas administrativas; Burocracia pública.

ABSTRACT This paper aims to discuss the coordination of the federal public administration at the time of administrative reforms, listing for this analysis the three major reforms of the twentieth century, namely: in 1938, with the creation of DASP; 1967, with the institution of the Decree-Law 200 and 1995 reform already in the democratic period. Two assumptions were considered: firstly, a pattern of continuity in the coordination of the three administrative reforms studied; secondly, the central organs of administrative coordination was strongly tied to the federal executive. The reforms were treated as critical junctures, i.e. moments in which a great discretion is shaping institutions, favoring changes in the type of coordination, whether it is more hierarchical (vertical) or more plural (horizontal). The main changes and difficulties in coordination pattern of the federal public administration in Brazil during periods of reform in screen were analyzed.

KeYwordS Coordination; Administrative reforms; Public bureaucracy. 


\section{Introdução}

A administração pública federal no Brasil teve seu grande salto de qualidade na década de 1930, antes disso a organização do Estado brasileiro era precária, permeada por vários elementos clientelistas e até patrimonialistas. Esses elementos não desapareceram com a burocratização do Estado, porém, foram drasticamente reduzidos frente a imperativos de uma burocracia pública baseada em critérios meritocráticos e procedimentais. Logo que surge um corpo burocrático mais robusto no interior do Estado brasileiro alguns problemas se elevam ao mesmo tempo. Conforme o aumento de pessoas, funções e instituições ligadas à administração pública mais se complica a delegação de funções entre esses diferentes corpos no interior da organização. Nesse sentido, a coordenação passa a ter centralidade para o aumento da capacidade decisória do aparelho de Estado e suas funções correlatas.

Nosso objetivo neste artigo é discutir a coordenação administrativa no interior da administração pública federal em momentos de reformas administrativas. Para a consecução desse objetivo formulamos duas hipóteses:

- A coordenação no interior da administração pública federal sempre foi um ponto nevrálgico das reformas administrativas. O objetivo das reformas era melhorar a coordenação entre os entes da administração pública, porém, falhas diversas dificultaram a implementação de uma coordenação efetiva. Em grande parte das reformas administrativas do século XX existiu uma ênfase política em alguma instituição no interior da administração pública federal para realizar a coordenação, o que sugere que houve uma continuidade no padrão institucional das reformas administrativas em centralizar a coordenação da administração pública federal em algum ministério ou órgão criado para esse fim específico; Órgãos centrais de coordenação nos diferentes períodos históricos estiveram fortemente condicionados pelas decisões políticas do executivo federal. Agências e ministérios serviram a propósitos de agenda bem estabelecidos pelo executivo federal, com ênfase na presidência da república.

Para nos guiar na averiguação dessas hipóteses formulamos quatro perguntas, as quais serão respondidas ao longo do artigo. São elas:

- Qual a configuração da coordenação administrativa no interior da administração pública federal em cada reforma?
- Houve alguma instituição no interior da administração pública federal que foi responsável pela coordenação?

- Quais foram os conflitos institucionais resultantes desses diferentes arranjos de coordenação?

- Existe algum traço de continuidade institucional entre essas reformas?

Alguns esclarecimentos acerca dos conceitos utilizados nesse trabalho devem ser feitos nesta breve introdução. Nosso conceito de reforma administrativa abrange duas dimensões, uma institucional e outra de funcionamento da burocracia pública (Costa, 2002). A dimensão institucional da reforma administrativa é relativa a mudanças no desenho organizacional da administração pública, quanto ao aspecto de funcionamento dessa administração a reforma toma o caráter de mudança dos procedimentos empregados pela burocracia para a realização de seus objetivos. Essa distinção é meramente analítica, pois mudanças no desenho organizacional estão associadas a alterações nas práticas administrativas.

Nosso entendimento sobre Coordenação no contexto organizacional do setor público é baseado nas considerações de Bouckaert, Peters e Verhoest (2010: 16) que a entendem como sendo os

[...] instrumentos e mecanismos que objetivam melhorar o alinhamento voluntário ou forçado de tarefas e esforços das organizações dentro do setor público. Esses mecanismos são usados no sentido de criar uma grande coerência, reduzindo a redundância, as lacunas e as contradições dentro e entre a gestão e a implementação de políticas.

Essa coordenação, ainda segundo Bouckaert, Peters e Verhoest (2010) pode ser de dois tipos. A coordenação vertical, na qual um órgão público superior na hierarquia governamental fornece diretrizes para a ação de outros órgãos hierarquicamente inferiores e a coordenação horizontal, em que órgãos com a mesma hierarquia coordenam suas ações entre si. Esses tipos de coordenação não são excludentes entre si, podem coexistir no interior das instituições ao mesmo tempo.

A coordenação, para além de reduzir lacunas e procedimentos repetidos no interior da administração pública, denota também a chamada capacidade estatal, que no entender de Skocpol (1985) significa conceber o Estado como um ator, assumindo que parte dos agentes estatais é capaz de formular e perseguir intenções e objetivos definidos a partir de suas próprias prioridades, e não como meras respostas a demandas sociais. Nesse sentido o Estado assume uma autonomia frente a grupos sociais em determinados 
procedimentos ${ }^{1}$. A coordenação, enquanto parte fundamental da capacidade estatal, favorece o uso do Estado pelos próprios burocratas, que podem moldar as instituições de maneira a não prejudica-los e até mesmo a beneficiá-los em seus arranjos. Esse uso do Estado pelos burocratas é altamente contingente, nem sempre se adequando a seus objetivos ou propostas, é dessa feita que a perspectiva neoinstitucionalista histórica não concebe o Estado como uma arena neutra de conflitos onde interesses se exprimem e se enfrentam. As ações do Estado são sempre historicamente determinadas, dessa maneira, segundo Skocpol (1985: 14):

Embora pesquisas entre nações possam indicar, em termos gerais, se um sistema de governo tem tendências "fortes" ou "fracas" em direção a uma ação estatal autônoma, o potencial total deste conceito pode ser realizado apenas em verdadeiros estudos históricos, que são sensíveis a variações estruturais e mudanças conjunturais dentro de dadas políticas.

Nosso conceito de instituições, neste trabalho, abarca uma perspectiva conflitiva, pois, para Thelen (1999: 382), as instituições são vistas como legados de processos históricos concretos, ou seja, lutas em torno das definições sobre o formato e finalidade das instituições. As instituições também não atuam isoladas umas das outras, um set, um grupo de instituições, em geral, se complementa e se reforça mutuamente, sugestão que nos faz pensar em diversos entes da administração pública federal dependendo e influindo nas suas relações recíprocas.

As instituições e as interações entre atores estão imersas na história em processos de critical junctures (conjunturas críticas) nos quais são feitas escolhas institucionais, as quais permitem apreender as relações políticas entre determinados grupos sociais (classes, grupos de interesse, entre outros) e as instituições. As relações entre escolhas institucionais e história das instituições têm profunda intimidade, tal como salienta Pierson (2004: 171-172):

Atores particulares, organizações ou instituições, são moldados em parte pelas suas relações espaciais com outros aspectos do conjunto social. Similarmente, um momento particular no tempo é parte de um amplo processo temporal. Eventos são

\footnotetext{
Para Skocpol (1985) o Estado pode formular e perseguir objetivos que não são simplesmente reflexos de demandas de interesses de grupos sociais, classes ou sociedades. Para a autora, abordagens sobre o Estado centradas em suposições societais ignoram que importantes mudanças sociais são consequência da atividade autônoma do Estado. Importante ressaltar que o argumento aqui não encerra a influência de diferentes grupos sociais nas decisões do Estado, porém, as minimiza frente ao arranjo estatal.
}

partes de várias sequências de eventos. Seu lugar naquelas sequencias pode desempenhar um papel crítico na determinação de seu significado. Assim, [esta perspectiva teórica] explora os conjuntos espaciais e temporais que fornecem elementos cruciais do contexto para qualquer objeto da pesquisa social.

Isso justifica, em parte, nosso recorte temporal neste trabalho, abordando, principalmente, conjunturas críticas no interior da burocracia pública federal, os momentos de reforma, ou seja, a mudança no desenho organizacional e do funcionamento da administração pública.

Dessa feita nosso estudo compreendeu as três principais reformas administrativas pelas quais passou a Administração Pública Federal brasileira no século XX, a saber: A reforma de 1937, durante o Estado Novo, a reforma de 1967, feita sob a batuta do regime militar e a reforma de 1995 , realizada sob os imperativos neoliberais durante o governo Fernando Henrique Cardoso. Cada um desses períodos está ligado a um projeto de Estado e, consequentemente, de sociedade. Nos anos de governo de Getúlio Vargas o projeto econômico colocado era o de um desenvolvimentismo reformista, procurando pressionar o desenvolvimento do Estado e suas instâncias para a modernização do país, sem grandes rupturas com os grupos sociais dominantes. A burocracia pública cumpriu papel fundamental nesse projeto, pois quem definiu a política econômica e a política social foram as cúpulas da burocracia civil e das Forças Armadas. O projeto militar na década de 1960 de integrar e desenvolver o país, e com isso difundir instituições estatais pelo país, favoreceu a ida do Estado para o mercado capitalista. Várias empresas estatais da área de infraestrutura foram criadas nesse período, assim como uma série de instituições no interior da administração pública responsáveis por serviços burocráticos diversos. A coordenação geral da administração pública do período ficou por conta do Ministério do Planejamento e Coordenação Geral, responsável pelos órgãos da administração indireta. Já na reforma do Estado de 1995 o contexto político apontava para o neoliberalismo e seu projeto correlato de diminuição do Estado em setores específicos, principalmente com a privatização de empresas públicas e redução de alguns serviços sociais, tal como saúde e previdência, por exemplo. A administração pública acompanhou esse projeto político de perto, tendo seu quadro de funcionários reduzido, assim como uma estrutura de coordenação montada no Ministério da Administração Pública Federal e Reforma do Estado (MARE), com vistas a "otimizar" o funcionamento da burocracia pública por meio do 
uso de mecanismos típicos de mercado, tal metas de produção aplicadas ao funcionamento da burocracia.

$\mathrm{O}$ artigo está dividido em quatro partes, sendo a primeira concernente à estruturação dos mecanismos da administração pública burocrática na década de 1930, principalmente a partir do Estado Novo (19371945) com a criação do Departamento Administrativo do Serviço Público (DASP). O segundo item é a respeito da reforma administrativa de 1967, durante o regime militar, que visou estruturar um novo arranjo de coordenação no interior da administração pública. $\mathrm{O}$ terceiro item trata da reforma administrativa da década de 1990, enfatizando o Plano Diretor da Reforma do Estado de autoria do então ministro Bresser Pereira, que trouxe modelos complexos de coordenação da gestão pública. Por último fazemos uma breve retrospectiva dos principais aspectos de cada um desses itens e elaboramos uma espécie de conclusão que tenta agregar alguns elementos comuns a essas tentativas de reformas e a questão da coordenação da administração pública.

\section{Modernização do Estado: a Criação de Estruturas de Coordenação na Década de 1930.}

A década de 1930 é um novo marco para a administração pública brasileira, pois grande parte do atraso das instituições burocráticas do Estado foi solucionado, possibilitando uma maior racionalidade no planejamento e execução das funções públicas da burocracia estatal. O intuito por trás da reforma administrativa da década de 1930 era, além de modernizar a máquina estatal, promover uma forte centralização das instâncias de elaboração e decisão política num núcleo central do Estado. Isso, segundo os principais ideólogos e gestores da reforma, seria para se evitar os compromissos clientelistas das oligarquias regionais e a forte pressão política dos políticos alocados no governo central, que tentavam solapar recursos destinados a projetos estatais para seus fins clientelistas pessoais. A reforma administrativa foi proveniente, também, de um fator conjuntural muito mais profundo. É conhecida a crise econômica que se abateu sobre a República Velha no final da década de 1920, derrubando o preço do café, principal produto de exportação daquele período, e sobre o qual se apoiava grande parte da economia do período. Com a crise econômica de 1929 o pacto do café com leite se desfez. O presidente Washington Luís, de São Paulo, em vez de apoiar um mineiro na eleição seguinte, apoiou o cafeicultor paulista Júlio Prestes. Os políticos mineiros revoltosos com a situação procuraram os latifundiários do Rio Grande do Sul. Antônio Carlos Andrada, à época governador mineiro, propôs aos gaúchos enfrentar abertamente São Paulo. A aliança entre gaúchos e mineiros foi construída sendo oferecido o cargo máximo de candidato à presidente a Getúlio Vargas, um gaúcho. Júlio Prestes ganhou as eleições, porém, não levou. Um golpe o retirou da presidência, assumindo Getúlio Vargas.

As primeiras medidas de Vargas, em âmbito estatal, tiveram como eixo dar uma nova tonalidade às instituições políticas, tornando-as mais "próximas" do presidente. Em 1933, reuniu-se a Assembleia Constituinte. O texto constitucional, aprovado em 1934, seguia os princípios de uma democracia liberal, tendo o federalismo preservado, mas o poder central, ampliado. Porém, a "ameaça" comunista, segundo Vargas, era um perigo iminente para a democracia brasileira. No intuito de "preservá-la", Vargas aproveitou o pretexto do levante comunista de 1935 para dar um golpe de Estado. Em 1937, apoiado pelo comando das Forças Armadas, por grande parte dos governos estaduais, ordenou que a polícia militar fechasse o Congresso Nacional. Cancelou as eleições presidências. Estava instaurada a Ditadura do Estado Novo. A Constituição de 1937 foi redigida pelo jurista Francisco Campos, baseada nas leis do regime fascista polonês, por isso o apelido de Constituição Polaca. Com essa constituição o Poder Executivo passou a ter seus poderes ampliados, os estados da federação perderam autonomia. Porém, mesmo com essa centralização o Estado Novo não rompeu com as antigas oligarquias regionais, os interventores (que assumiram o papel de governadores), no geral, eram ligados a oligarquias. O congresso não legislava. Apenas o presidente o fazia, por meio de decretos-leis. Segundo o historiador Boris Fausto (1972: 87) “[...] o Estado Novo realizou plenamente a inclinação centralizadora, revelada desde os primeiros meses após a Revolução de 1930".

Todos esses esforços de centralização política no executivo federal requeriam uma burocracia capacitada e um arranjo institucional capaz de atingir o objetivo de alijar os poderes oligárquicos das principais decisões estatais. A maneira encontrada para isso foi a criação de uma espécie de superministério, capaz de congregar várias funções e contar com um corpo de burocratas experientes. Segundo Siegel (1966: 46), a

[...] necessidade para uma reforma burocrática não foi articulada entre as massas. Vargas empreendeu a reforma por conta da natureza corrupta e ineficiente da maquinaria administrativa que ele herdou como um obstáculo formidável a seus novos programas. 
Em 1934, Vargas convocou oficiais da burocracia ligados às relações exteriores para avaliar e propor uma nova organização para a administração. Um desses oficiais era Maurício Nabuco, o qual listou uma série de recomendações sobre a classificação do pessoal da administração pública, porém, teve seus esforços dirimidos frente ao medo de seus estudos e conclusões não caberem no orçamento federal. Nabuco se retirou da função de reorganizar a administração pública, sendo que tal função ficou por conta de Luís Simões Lopes, um consultor do presidente Vargas sobre a reforma administrativa. O trabalho de Simões Lopes e seu grupo resultou na primeira legislação para a reorganização do serviço civil no Brasil. A "Lei do Ajuste", de 1936², favoreceu a criação de órgãos encarregados da organização, coordenação e desenvolvimento do serviço público, a saber, o Conselho Federal de Serviço Civil e as Comissões de Eficiência. Segundo Siegel (1966: 47) "[...] as comissões de eficiência foram os olhos e os ouvidos do Conselho dentro dos ministérios, encarregados das melhoras efetivas na organização e gestão pública”. O staff de Simões Lopes foi movido por uma promessa de uma reorganização política revolucionária dentro da administração pública brasileira, porém, mesmo com um pessoal altamente qualificado os esforços não foram capazes de romper com vicissitudes arraigadas às instituições da administração federal. Frente a isso, e associado a outros fatores, tal como o fechamento do regime, Vargas, na constituição de 1937, centralizou o poder sobre o chefe do executivo e eliminou várias checagens do poder. $\mathrm{O}$ artigo $67 \mathrm{da}$ Constituição de $1937^{3}$ afirmava que um departamento administrativo seria estabelecido sobre o controle do presidente, com a responsabilidade para estudar e controlar todos os assuntos organizacionais do governo, auditar a execução orçamentária, a seleção, o desenvolvimento e o controle dos servidores públicos, assim como o desenvolvimento e controle dos

\footnotetext{
${ }^{2}$ Lei 284 de 1936 (BRASIL, 1936)

Art 67 - Haverá, junto à Presidência da República, organizado por decreto do Presidente, um Departamento Administrativo com as seguintes atribuições:

- o estudo pormenorizado das repartições, departamentos e estabelecimentos públicos, com o fim de determinar, do ponto de vista da economia e eficiência, as modificações a serem feitas na organização dos serviços públicos, sua distribuição e agrupamento, dotações orçamentárias, condições e processos de trabalho, relações de uns com os outros e com o público;

- organizar anualmente, de acordo com as instrucões do Presidente da República, a proposta orçamentária a ser enviada por este à Câmara dos Deputados;

- fiscalizar, por delegação do Presidente da República e na conformidade das suas instruções, a execução orçamentária (BRASIL, 1937).
}

sistemas de materiais e especificações, a assessoria de referências legislativas para o presidente. O efeito do Artigo 67 foi a centralização do corpo administrativo do Estado e as atividades de reforma. Esse artigo da Constituição concebia um órgão de administração geral, tal como recomendado pelo administrador público estadunidense Willoughby ${ }^{4}$. A influência estadunidense se mostrou com bastante força no caso brasileiro, tendo "importado" um modelo de agência centralizadora para dentro da administração pública, consequentemente, centralizando várias funções.

O Departamento Administrativo do Serviço Público (DASP) foi criado no início do Estado Novo pelo Decreto-Lei $n^{\circ} 579$, de 30 de julho de 1938 (BRASIL, 1938). O DASP foi uma agência com amplos poderes, responsável por executar uma série de tarefas, abrangendo desde estudos pormenorizados de repartições, departamentos e estabelecimentos públicos, selecionar candidatos aos cargos públicos federais até auxiliar o Presidente da República no exame dos projetos de lei submetidos à sanção. A agência ocupava uma posição de destaque dentro da organização da administração pública federal. A criação do DASP representou uma espécie de critical juncture no interior da administração pública brasileira, pois mudou a forma de organização e funcionamento da burocracia estatal, dando novos contornos à relação entre os entes da administração e da ação do Estado frente à economia e aos grupos sociais no interior do Estado.

Para Nogueira (1998: 94), o DASP foi o grande símbolo do Estado novo, dotado de grande força e prestígio, nesse sentido, a agência:

[...] funcionou como órgão de inovação e modernização administrativa, liderando a efetiva organização do aparato público brasileiro e atuando como centro irradiador de influências renovadoras, peça estratégica de um sistema racionalizador no âmbito do Poder Executivo federal.

Segundo as palavras de Guerreiro Ramos (1983:346), um burocrata do DASP à época:

Pode-se afirmar que, entre 1930 e 1945, ocorreu verdadeira revolução administrativa no Brasil, tal o porte das modificações de estrutura e de

\footnotetext{
${ }^{4}$ Várias missões brasileiras fizeram estágios nos Estados Unidos para apreender com os gestores públicos daquele país técnicas e métodos de gestão da administração pública. Escritos de Luther Gulik, Charles E. Meriam e Louis Brownlow eram amplamente conhecidos em 1938. Vários desses artigos foram impressos em português e apareceram na nova revista profissional do DASP, a Revista do Serviço Público (Cf. Graham, 1968)
} 
funcionamento que se verificaram em nosso serviço público federal.

Para Fausto (1972) o Estado novo aumentou o raio de ação das atividades do Estado, acentuando a importância aos órgãos onde os quadros técnicos tiveram um papel de destaque. Isso foi feito em claro contraste com a política administrativa da República Velha (1889-1930), na qual o serviço público prestava-se à política de patronagem da oligarquia, pois quase inexistiam concursos para admissão de funcionários, e seus quadros qualificados se restringiam a uma pequena elite. Para Fausto (1972: 103-104):

O regime implantado em 1937 procurou reformular a Administração Pública, transformando-a, ao mesmo tempo, em um agente da modernização. Buscou-se criar uma elite burocrática, desvinculada da política partidária, que o Estado Novo definia como uma "contraditória e anárquica manifestação das correntes representativas de interesses específicos". [...] O decreto-lei de 1938 deu ao DASP poderes bastante amplos, incluindo a instituição de um controle central sobre o pessoal e o material, assim como a responsabilidade, de dar assistência ao Presidente na revisão das propostas legislativas. Na realidade, pretendia o decreto que o DASP fosse um super-ministério, com papel importante na distribuição dos gastos governamentais.

O DASP, sem dúvida, foi uma grande novidade da administração pública brasileira, conjugando expertise burocrática com forte centralização de tarefas (Siegel, 1966; Graham, 1968; Lambert, 1968; Geddes, 1994). Porém, isso teve um custo para a instituição, refletindo em conflitos com outras instituições e com o próprio arranjo dos grupos sociais alocados dentro do serviço público. O plano de Getúlio para o DASP era que ele se tornasse uma espécie de superministério, conjugando planejamento orçamentário e controle sobre os gastos do Estado. Porém, várias dessas funções permaneceram relativamente subdesenvolvidas. A compra de materiais nunca foi perfeita, pois o excesso de centralização era um entrave burocrático para a aquisição de equipamentos e insumos necessários para a realização de várias atividades da administração. A necessidade de aprovação de um órgão central da estrutura administrativa resultou numa alta formalização da organização governamental ${ }^{5}$. O planejamento orçamentário também nunca foi uma pauta fácil no interior do Estado Novo. Existia uma grande pressão em torno do orçamento. Pressão essa proveniente do próprio arranjo institucional, mas reflexo direto das disputas em âmbito dos grupos dominantes na própria sociedade. A elaboração do orçamento era de responsabilidade do Ministério da Fazenda, órgão ocupado, em sua grande parte, por uma burocracia "viciada", com acordos entre "elites" locais, que demandavam do orçamento federal recursos para manter seus vínculos clientelistas regionais. O projeto do Estado Novo varguista, embora fizesse algum tipo de aliança com as oligarquias regionais, tentava minimizá-las no interior do governo. Retirar a elaboração do Orçamento de dentro do Ministério da Fazenda se mostrou uma tarefa inglória para os burocratas daspianos. Tal como já dissemos, o orçamento federal era amarrado a diversos compromissos políticos estabelecidos entre deputados e senadores juntamente a suas bases regionais, minando recursos escassos do Estado e transferindo para oligarquias regionais. Vargas tentou dar cabo a essa situação, tentando levar a elaboração e fiscalização do orçamento para dentro do DASP. A tentativa acabou em fracasso, pois o orçamento continuou sob a responsabilidade do Ministério da Fazenda até 1945, sendo que a transferência da elaboração e controle do orçamento para o DASP foi meramente nominal. Para Fausto (1972: 104) o DASP não chegou a ser uma agência com tanta centralização sobre os assuntos da administração pública

[...] porque o Ministro da Fazenda se opôs fortemente a uma diminuição de seus poderes. Alcançou-se um compromisso, com a formação de uma comissão especial de orçamento, onde o controle do DASP foi temperado por outras influências.

Desse modo, uma das grandes dificuldades de Vargas, durante o Estado Novo, foi driblar as oligarquias regionais e seu controle sobre uma série de recursos estatais. Nesse ponto a centralidade DASP no desenho da administração pública se mostrou inadequado para a tarefa.

Segundo Nunes (1997), o DASP foi uma expressão clara daquilo que ele conceituou como insulamento burocrático, qual seja: o processo de proteção de um núcleo técnico do Estado contra a interferência do

\footnotetext{
5 Aqui se revela a característica de coordenação horizontal do DASP, pois embora tivesse mais poderes do que outros ministérios e departamentos sua influência não era hierárquica, pois se encontrava ainda no mesmo nível organizacional de outros ministérios e departamentos.
} 
público ou de outras organizações intermediárias. Ao núcleo técnico é atribuída a realização de objetivos específicos. Esse insulamento significa uma redução do escopo da arena em que interesses e demandas de diversos grupos possam ser atendidos. Ainda segundo Nunes, esta redução da arena é efetivada pela retirada de organizações cruciais do conjunto da burocracia tradicional e do espaço político governado pelo congresso e pelos partidos políticos. Isso resguardaria essas organizações contra tradicionais demandas burocráticas ou compromissos oligárquicos que minam a "eficiência" estatal. Barbara Geddes (1994) é outra autora que trabalha com o conceito de insulamento burocrático. Para o caso do DASP, tal autora defende com mais força a ideia, afirmando que os burocratas precisam de proteção em relação aos políticos e seu ímpeto em transformar os recursos estatais em benefícios particularistas para apoios ou mesmo demandas locais. O intuito varguista com o DASP era dar a essa agência grande autonomia frente ao sistema político vigente, numa clara tentativa de alijar interesses oligárquicos do interior de setores estratégicos da administração pública brasileira.

Durante o Estado Novo o DASP sofreu de um processo de hipertrofia, pois, segundo Siegel (1966), cada atividade original da agência, colocada pela Constituição de 1937, foi amplificada para incluir muitas atividades subordinadas. Novas funções como o controle de obras públicas foram adicionadas à agência. Para Siegel, essa super expansão do DASP em seus primeiros sete anos, em conjunção com a ênfase no controle centralizado, colocou várias dificuldades para a agência. Dentre as principais, a falta de eficiência administrativa e a não realização das novas funções, que, muitas vezes, ficavam apenas no papel, permanecendo como "fantasmas" dentro da organização administrativa, pois não tinham uma existência real. Outra crítica frequente ao DASP, segundo Lambert (1968: 178), é a falha radical da inabilidade de estabelecer controle sobre a administração do pessoal da administração pública, que era o seu principal objetivo.

ODASP não foi apenas um cenário de improvisações mal sucedidas. Ainda segundo Siegel (1966: 48) uma das improvisações organizacionais mais interessantes do DASP foi o conceito de Sistema Coordenador, cuja principal função era zelar pela coordenação da administração federal como um todo. Para isso foram criadas agências de apoio responsáveis pela ligação ministerial com a administração central, no caso a presidência da república. A responsabilidade técnica por essa ligação era do DASP, que, no limite, também detinha uma parcela de poder nessa ponte entre os ministérios e a Presidência. Para além da coordenação interministerial o DASP tomou parte na coordenação entre a Administração Pública Federal e os entes da federação. Após a substituição dos governadores dos estados por interventores, Vargas ordenou que a ligação oficial entre o governo central e os estados seriam manejadas pela Comissão para o Estudo das Relações de Estado. O DASP obteve muito controle nessa comissão, e Simões Lopes, foi um influente membro dessa Comissão. De fato, o DASP foi chamado com frequência a auxiliar os interventores com problemas administrativos. Um dos resultados principais dessa Comissão foi o auxílio na criação de Departamentos Administrativos no interior dos estados, os chamados, à época, daspinhos ${ }^{6}$. O DASP, durante o Estado Novo, teve uma série de funções dentro da Administração Pública Federal, dentre as principais se destaca a coordenação. Coordenação aqui entendida como instrumentos e mecanismos que objetivam melhorar o alinhamento de tarefas e esforços de instituições e organizações dentro da administração pública.

Em 1945 o Estado Novo já mostrava sinais de esgotamento entre as classes e suas frações de apoio. Nesse ano o General Góis Monteiro, apoiador do golpe de 1937, afastou Getúlio da presidência. O governo foi entregue a José Linhares, presidente do Supremo Tribunal, que logo depois o passou ao primeiro presidente do Brasil eleito por voto direto e secreto: o general Eurico Gaspar Dutra.

Após 1945, o DASP é esvaziado e negligenciado. José Linhares nomeou vários parentes e amigos para cargos importantes dentro da administração pública, quebrando a lógica de coordenação do DASP sobre as diversas instituições e organizações do serviço público brasileiro. Isso provocou grande descontentamento nas fileiras da agência, que teve seus cargos "abandonados" em grande número, com a saída de vários importantes e qualificados burocratas?

\footnotetext{
${ }^{6} \mathrm{O}$ termo daspinho é incorreto e aqui mantemos a nomenclatura meramente por sua difusão na literatura. Segundo Codato (2008: 43-44) os Departamentos Administrativos não eram divisões estaduais do DASP. Eram duas estruturas burocráticas muito diferentes entre si. O DASP dizia respeito ao serviço civil federal, elaborando uma política de reorganização orçamentária eficiente, enquanto que os Departamentos Administrativos estaduais se ocupavam da gestão dos negócios políticos estaduais e não um mero corpo burocrático isolado das pressões políticas. Além dessa diferença de funções a composição de um e outro aparelho era bastante distinta. O DASP continha técnicos concursados, uma burocracia profissional, e os "daspinhos", por sua vez, eram integrados por políticos profissionais.

7 O Decreto-Lei 8323-A de 7 de Dezembro de 1945 retirou uma série de poderes do DASP, devolvendo-os aos diversos ministérios, principalmente a seu rival, o Ministério da Fazenda. Nesse sentido, o artigo primeiro do decreto é bem exemplar.

- Art. $1^{\circ}$ O Departamento Administrativo do Serviço Público (D. A. S. P.) diretamente subordinado ao Presidente da República, é um órgão de estudo e orientação dos problemas da administração
} 
O esvaziamento do DASP, segundo Lambert (1968) beneficiou os outros ministérios, os quais tinham seus poderes e raios de influência limitados pela hipertrofia do DASP, assim como as oligarquias locais voltaram a usar a máquina burocrática para o controle do orçamento e mecanismos para favorecimentos pessoais e, consequentemente, de classe. Durante a década de 1940 os interesses desenvolvimentistas ensaiaram algumas ações de maior alcance junto a setores estratégicos da economia brasileira. Durante o governo Dutra, em 1947, o DASP elaborou uma proposta de plano de desenvolvimento, intitulada SALTE (Saúde, Alimentação, Transporte e Energia). O controle orçamentário ficava por conta do Ministério da Fazenda, que elaborou sua própria lista de projetos para serem avaliados pelo Congresso. As dificuldades para implantação do plano foram muito grandes, justamente pela pouca previsão das restrições legais para a execução do orçamento e os aspectos que a economia brasileira que dificultavam a administração do plano. Segundo Lambert (1968: 50), frente a essas dificuldades Bittencourt Sampaio, chefe do DASP no período, forneceu, clandestinamente, uma versão do orçamento feito pela agência à comissão de orçamento do plano SALTE. A proposta da comissão foi uma cópia de carbono do documento vindo do DASP. Fato é que o DASP, pós-1945, lutou para sobreviver, abandonando várias de suas pautas principais, tal como a centralização e o controle, ficando com tarefas menores no interior da administração.

Este padrão de regressão do DASP foi parcialmente estagnado com o retorno de Vargas à presidência em 1951. Uma reclassificação mais completa e sistemática dos servidores públicos foi iniciada, com a realização dos exames de admissão retomados e o controle de pessoal sendo removido dos ministérios individuais. Porém, diferentemente do Estado Novo, a ênfase "técnica" na burocracia não foi levada com tanta firmeza por Vargas, abrindo a burocracia pública para uma maior disputa por vagas e cargos comissionados, ou mesmo os cargos intitulados de extranumerários ${ }^{8}$. Ainda em 1951 o DASP trabalhou

pública, exercendo as suas atividades no sentido de cooperação e articulação com os órgãos do serviço civil federal.

- Parágrafo único. As atividades executivas e fiscalizadoras de administração geral ou específica competirão aos órgãos ministeriais próprios.

${ }^{8}$ Existe algum debate sobre a real função dos cargos extranumerários. A principal delas seria comportar as disputas entre facções políticas em disputa para o preenchimento de cargos, ou seja, a criação desses cargos diminuiria a pressão desses grupos sobre a máquina estatal. A segunda função, que não exclui a primeira, seria a tentativa de manter os vínculos de patronage do executivo federal sobre os grupos sociais para obter apoio e aprovar seus planos, orçamentos e outros dispositivos sem maiores conflitos. Esse debate tem muita relação com o sistema partidário vigente no período histórico citado. Por em conjunto com outros ministérios, com objetivo em melhorar a organizações, condições e métodos de trabalho. Percebe-se claramente que o DASP já não tinha mais uma função de coordenação no interior da Administração Pública Federal, tal como teve no Estado Novo. Embora o segundo governo de Vargas tenha dado novo ânimo à agência isso não a recolocou em sua antiga posição central.

\section{A Tentativa de Reforma da Administração de 1967: Um Esboço de Gerencialismo?}

Segundo Lambert (1968: 187), os erros das reformas pré-1967 consistiram na tentativa de uma reforma geral, com um pequeno grupo de experts isolados da vida normal das organizações que eles tentavam mudar. Esse erro foi minimizado na tentativa de reforma de 1967, pois os objetivos reformistas eram bem mais modestos do que durante o Estado Novo9. A conjuntura do período na qual foi implantada a tentativa de reforma era, novamente, uma ditadura, só que dessa vez militar. O Regime Militar estava envolvido em uma política desenvolvimentista, favorecendo o fortalecimento da infraestrutura brasileira, na tentativa de atrair investimentos e fortalecer a frágil indústria brasileira. Nesse sentido, pode-se falar de uma expansão do Estado brasileiro, que segundo Martins (1985), foi realizada por um meio de dois movimentos integrados, tanto por forças centrípetas, concentrando recursos financeiros e decisões normativas ao nível do Executivo federal, assim como por forças centrífugas, delegando atribuições a agências relativamente independentes para aplicar recursos e tomar decisões.

O Presidente em 1967 era Costa e Silva e sua preocupação com o tamanho e a eficiência da administração pública foi demonstrada com a convocação de um grupo responsável por formular um plano de reforma para a administração, chefiado pelo burocrata Nazaré Dias. Os resultados das elaborações desse grupo foram publicados no Decreto-Lei n ${ }^{\circ} 200$, de 25 de fevereiro de 1967. Segundo Bresser Pereira (1998: 169-170), as linhas gerais do Decreto-Lei podem ser elencadas da seguinte maneira:

- Cinco "princípios fundamentais da reforma": planejamento, descentralização, delegação de competência, coordenação e controle;

razões de espaço e tempo não iremos nos deter nessas análises neste trabalho.

9 O Artigo 146 do Decreto-Lei $\mathrm{n}^{\circ} 200$ colocava que a Reforma Administrativa seria realizada por etapas e, na medida em que fossem efetivados os processos, as providências necessárias seriam tomadas para a sua execução (BRASIL, 1967). 
- Planejamento para o desenvolvimento, implicando na expansão das empresas estatais, enquanto a descentralização levava à disseminação dos órgãos dotados de ampla autonomia administrativa e semi-independentes;

- A delegação de competências requeria o fortalecimento das carreiras dos servidores públicos baseadas no mérito;

- Diretrizes gerais para um novo Plano de Classificação de Cargos;

- Reagrupamento de departamentos, divisões e serviços em 16 ministérios.

Esses princípios do Decreto-Lei 200 marcaram a tentativa de descentralização da Administração Pública Federal, cuja ênfase era fortalecer a administração indireta, principalmente as empresas públicas, autarquias, empresas de economia mista, entre outras organizações que já existiam desde $1938^{10}$. O Decreto-Lei 200 é um marco institucional das transformações pela qual o Estado estava passando na década de 1960, assim, conjugando diretrizes normativas centralizadas de planejamento ao nível do Executivo federal com diversificação da natureza dos órgãos governamentais promoveu a descentralização funcional do Estado. Em suma, a reforma de 1967 postulou um novo arranjo na distribuição de funções no interior da burocracia estatal, agora formalmente e hierarquicamente dividida em direta e indireta.

$\mathrm{O}$ crescimento da administração indireta foi muito grande, num curto período de tempo foram estabelecidas 267 empresas públicas e aproximadamente 68 autarquias e fundações (Costa, 2002). Com esse processo de descentralização da administração direta uma maior autonomia foi dada a administração indireta, viabilizando um projeto de industrialização com base em grandes empresas estatais de infraestrutura e serviços públicos. Essa ação empresarial do Estado não foi de modo algum acidental, foi pautada como resultado de uma longa discussão política que criou condições para que o Estado pudesse obter legitimidade junto aos diversos setores sociais para a implantação de órgãos da

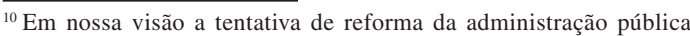
de 1967 consolidou a divisão da administração pública em dois níveis: administração pública direta e indireta. A administração pública direta é aquela composta por órgãos ligados diretamente ao poder central, federal, estadual ou municipal. São os próprios organismos dirigentes, seus ministérios e secretarias. Enquanto que a administração pública indireta é aquela composta por entidades com personalidade jurídica própria, que foram criadas para realizar atividades de Governo de forma descentralizada. São exemplos as Autarquias, Fundações, Empresas Públicas, Agências Reguladoras e Sociedades de Economia Mista. Por mais que essa divisão já estivesse colocada pelo próprio DASP em 1938 ela só foi implementada no rigor da letra a partir do Decreto-Lei 200.
}

administração indireta com grande autonomia e com vastos recursos à sua disposição (Martins, 1985).

A reforma administrativa de 1967 tinha como alvo uma mudança no desenho organizacional da administração pública federal, assim como a alocação de novas funções aos burocratas, cujas funções tinham sido divididas em dois níveis (administração direta e indireta). Nesse sentido, a reforma de 1967, a nosso ver, pode ser considerada uma critical juncture para a administração pública brasileira, pois trouxe importantes inovações, as quais já vinham sendo traçadas nas décadas passadas, mas não com o mesmo arranjo que o Decreto-Lei 200 colocou. A colocação do ministro Hélio Beltrão, em parte, confirma esse caráter de inovação da reforma, chamando-a de "revolução silenciosa" na administração pública brasileira. Os propósitos do Decreto-Lei 200 eram contornar a rigidez das estruturas da administração direta e introduzir o espírito gerencial privado na administração do setor paraestatal ${ }^{11}$.

A estrutura institucional para tal projeto já tinha sido construída nas décadas anteriores, com a criação nos anos 1940 e 1950 de algumas empresas públicas, ao mesmo tempo em que o Banco Nacional do Desenvolvimento Econômico (BNDE), também criado na década de 1950 , se tornava uma agência estratégica para o desenvolvimento e o Banco Central, uma espécie de guardião da moeda. A estrutura de coordenação desse arranjo foi capitaneada pelo Ministério do Planejamento e Coordenação Geral (que mais tarde se tornaria a Secretaria de Planejamento da Presidência da República, SEPLAN), que, segundo Bresser Pereira (1998: 170):

[...] passou a dispor, potencialmente, de maior autoridade do que qualquer outro ministério. Isto deveu-se ao fato de este órgão desempenhar o papel de agência central no que concerne ao sistema de planejamento (mantendo unidades em cada ministério e em cada entidade da administração descentralizada, isto é, empresas estatais, fundações públicas e autarquias) e ao sistema de contabilidade e auditoria interna (anteriormente uma atribuição do Ministério da Fazenda). Mais tarde, a SEPLAN acumulou também a atribuição estratégica de exercer o controle central sobre todas as empresas estatais,

\footnotetext{
${ }^{11}$ Representativo disso é o Artigo. 27 do Decreto-Lei 200 (BRASIL, 1967), o qual afirma que: Art. 27. Assegurada a supervisão ministerial, o Poder Executivo outorgará aos órgãos da Administração Federal a autoridade executiva necessária ao eficiente desempenho de sua responsabilidade legal ou regulamentar.

- Parágrafo único. Assegurar-se-á às empresas públicas e às sociedades de economia mista condições de funcionamento idênticas às do setor privado cabendo a essas entidades, sob a supervisão ministerial, ajustar-se ao plano geral do Governo.
} 
fundações públicas e autarquias; sobrepondo-se ao controle setorial exercido até então apenas pelos diversos ministérios.

As dificuldades eram inerentes ao modelo de reforma adotado pelos militares, pois aquilo que tinha sido projetado para ser uma divisão minimamente racional do trabalho, no âmbito do Estado, foi convertido num relacionamento tenso entre níveis administrativos. A reforma nunca foi completada e a consequência foi a perda de coordenação da administração direta sobre a indireta. As duas administrações (direta e indireta) tinham perfis diferentes (Martins, 1985; Costa, 2002), a administração direta com uma baixa qualificação e organização enquanto que a administração indireta era de perfil gerencial, quase empresarial. A coordenação, que era o grande mote da reforma de 1967 , foi uma das grandes protagonistas da falha em completar tal reforma. A falta de coordenação entre as empresas públicas e autarquias com as instituições da administração direta foi em grande medida responsável pelo fracasso do plano, isso devido à fraca institucionalização, por parte do Decreto-Lei 200, de normas para regulamentar e coordenar a expansão da administração indireta, tornando o relacionamento conflituoso entre os diferentes níveis da administração pública.

Interessante notar que a estrutura de coordenação da tentativa de reforma de 1967 não divergia em muito do modelo daspiano, no qual um órgão da administração direta estava encarregado de tomar para si a maior parte dos mecanismos de controle, ficando responsável pela gestão de vários programas em diversos ministérios. Esse é um padrão que parece estar arraigado às instituições da administração pública brasileira.

Nesse ponto subjaz uma crítica ao argumento de Bresser Pereira (1998) que viu na tentativa de reforma de 1967 um esboço de gerencialismo avançado. Não concordamos com tal hipótese, pois os mecanismos, por mais que vinculassem as empresas públicas, empresas de economia mista e autarquias a uma lógica de gestão empresarial capitalista privada não dispôs de mecanismos inovadores, caindo, mais uma vez, naquilo que Bresser Pereira erroneamente chama de reformas burocráticas. Afinal, toda reforma administrativa é, em si, burocrática. O que muda é a ênfase do processo, que pode ser dada a características burocráticas mais fechadas ao próprio universo da burocracia do aparelho de Estado ou buscando elementos do mercado na gestão das empresas e órgãos públicos.

A tentativa de reforma de 1967, a nosso ver, não resultou numa pretensa ruptura com o padrão das reformas passadas na administração pública brasileira. Ao que nos parece, as reformas administrativas no Brasil tem uma espécie de continuidade institucional, nesse sentido, dependentes das trajetórias institucionais dos próprios órgãos da administração pública federal.

\section{A Reforma do Aparelho de Estado Brasileiro da Década de 1990}

Com vistas às crescentes problemáticas geradas pela ineficiência da burocracia estatal, tais como, atrasos em obras públicas, excesso de burocracia atravancando os serviços prestados pelo Estado, no final dos anos 1970 começou a crescer um movimento em prol de reformar o serviço público. Essa reforma começou nos países desenvolvidos, principalmente nos de língua inglesa (Pollitt, 1990), e seus princípios se baseavam na descentralização da burocracia, enxugamento da máquina estatal, princípios de confiança e responsabilização dos funcionários públicos, gerência por resultados, entre outros. Esses pressupostos básicos das reformas administrativas se espalharam pelo mundo, atingindo também o Estado brasileiro. Essa difusão institucional das reformas administrativas se deu em ampla escala, principalmente na década de 1980, atingindo o Reino Unido, Estados Unidos, Nova Zelândia, Austrália, entre outros países. O nome que esse movimento de reformas recebeu ao redor do globo foi de $\mathrm{New}$ Public Management (NPM), aqui traduzido como Nova Administração Pública (NAP) ${ }^{12}$. No Brasil, tal reforma chegou com relativo atraso, devido à ampla resistência aos imperativos de tais reformas administrativas. Basta lembrar que a Constituição de 1988 reivindicava mais presença e mais serviços sociais prestados pelo Estado. Segundo críticos, tal como Bresser Pereira (1998), a constituição de 1988 remeteu a administração pública brasileira de volta à década de 1930, não acompanhando os avanços das reformas administrativas ao redor do mundo. O regime jurídico único, para Bresser Pereira, teria engessado toda a tentativa de autonomia da administração pública da década de 1950, balizando por baixo o serviço estatal, priorizando o servidor ao invés do serviço prestado à sociedade. Seguindo

\footnotetext{
${ }^{12}$ Existe um pressuposto organizacional por trás das propostas das reformas baseadas nos preceitos da NAP. O pressuposto é que a especialização resulta em ganhos de eficiência. Esta eficiência pode ser tanto para pequenos corpos no interior de uma burocracia até mesmo para amplos departamentos e instituições. Seguindo esta lógica, grandes organizações têm sido desmanteladas em pequenas partes, cada qual com seu nível de autonomia garantido. Assim como o aumento da descentralização e uma consequente expansão no número de agências "autônomas" no interior da burocracia pública.
} 
essa linha, a estrutura administrativa brasileira ajudou a agravar a crise fiscal da década de 1970, em que o Estado gastava mais do que arrecadava, despendendo recursos excessivos com a burocracia pública, não dando a devida atenção aos avanços que as reformas administrativas estavam realizando nos países que as tinham implementado. Essas críticas miravam justamente a junção das áreas estratégicas do Estado, tal como a alta burocracia de Estado, defesa e planejamento econômico com as áreas sociais, previdência e serviços sociais. Isso, segundo os críticos, impediria um maior desenvolvimento do Estado, pois a fusão dessas duas dimensões no Estado seria prejudicial para uma administração competente e baseada em resultados.

Tal quadro se alterou na década de 1990 no Brasil. Em 1994 foi eleito o presidente da República Fernando Henrique Cardoso (FHC), pelo Partido da Social Democracia Brasileira (PSDB). Logo assumindo seu mandato, em 1995, o presidente criou o Ministério da Administração Federal e Reforma do Estado (MARE), tendo como ministro Luiz Carlos Bresser Pereira. Esse ministério seria o responsável por reformar o serviço público, assim como trazer uma nova mentalidade para a burocracia brasileira, baseada em reformas ocorridas em outros países capitalistas que buscavam a eficiência da administração pública. Segundo Abrucio (2007: 71), a plataforma do MARE

[...] foi erigida a partir de um diagnóstico que ressaltava, sobretudo, o que havia de mais negativo na Constituição de 1988 e apoiava-se fortemente no estudo e tentativa de aprendizado em relação à experiência internacional recente, marcada pela construção da nova gestão pública.

Ainda em 1995 foi instituído o Plano Diretor da Reforma do Estado (PDRE) (Brasil, 1995), contendo um novo modelo de gestão para o setor público a partir da redefinição do papel do Estado e da instauração de um novo modelo de administração por resultados. O PDRE possuía três elementos principais: a) a transformação do papel do Estado e das estratégias de desenvolvimento; b) as funções vitais da burocracia pública; e c) os modelos institucionais diferenciadores. $\mathrm{O}$ primeiro elemento era uma clara crítica às políticas desenvolvimentistas centradas na política Estatal e na crença de que fora do Estado não existiria desenvolvimento. $\mathrm{O}$ segundo e terceiro elementos tinham a intenção de transformar os órgãos públicos, por meio de vigorosas reformas em seus mecanismos institucionais, em competidores de mercado, ou seja, moldar instâncias da burocracia pública para concorrer com outras empresas no mercado. $\mathrm{O}$ grande mote da reforma era desconstruir a estrutura da administração pública federal, que, no diagnóstico do MARE, era vista como grande, ineficiente e lenta. A solução era a privatização de uma série de empresas públicas, transferindo seus ativos para a iniciativa privada.

A reforma administrativa, iniciada em 1995, foi, a nosso ver, mais um momento crítico no arranjo da administração pública federal. O novo modelo, importado dos países desenvolvidos (NAP), trouxe novas ideias sobre a organização e o funcionamento da administração pública brasileira, repercutindo diretamente na ação do Estado.

Com a privatização de uma série de empresas públicas, principalmente do setor de mineração, energia e telecomunicações, surgiu a necessidade de regulamentar a ação da iniciativa privada. Para isso foram criadas as agências reguladoras, as quais ficaram encarregadas de exercer a coordenação do Estado sobre os setores que foram alijados de seu núcleo. Essas agências teriam a função de estabelecer os marcos regulatórios em mercados de grande impacto social. As principais agências criadas no período compreendido entre 1995 e 2002 foram a Agência Nacional de Vigilância Sanitária, Agência Nacional de Saúde, Agência Nacional de Energia Elétrica, Agência Nacional de Telecomunicações e Agência Nacional do Petróleo.

O pretenso diagnóstico que motivou a criação das agências regulatórias era a falta de flexibilidade e autonomia de corpos técnicos específicos para delimitarem um universo de ação de tais empresas em seu relacionamento com os clientes e fornecedores. Assim, as agências reguladoras, no período FHC sofreram pouco controle por parte do governo, e, consequentemente, uma ampla autonomia frente aos poderes da república para estabelecerem seus respectivos marcos regulatórios ${ }^{13}$. Essa tendência em autonomizar instituições da administração pública indireta em relação à coordenação mais enfática da administração direta é uma falha do próprio modelo da NAP. Isso é o que apontam pesquisas recentes (Bouckaert, Peters, Verhoest, 2010), afirmando que as reformas administrativas, baseadas nos modelos da NAP, careciam de elementos efetivos de coordenação entre os níveis da administração pública ${ }^{14}$.

\footnotetext{
${ }^{13} \mathrm{O}$ problema nessa autonomia é evidente. Houve um claro aumento da influência do setor privado sobre as agências regulatórias, no intuito de flexibilizar os marcos regulatórios e como resultado um favorecimento da iniciativa privada, a qual teve seus padrões de atuação no mercado claramente relaxados. A crise do "Apagão" em 2001, para além de problemas históricos de infraestrutura no setor energético, foi um momento em que a falta de coordenação da administração direta sobre a indireta se mostrou acentuada.

${ }^{14}$ A coordenação sempre foi um problema nas reformas da NAP, principalmente após a primeira onda de reformas. A segunda onda de reformas da NAP, já na década de 1990, procurou dirimir os problemas de coordenação tentando recentralizar tarefas fundamentais da
} 
Em 1998 é criada a Emenda Constitucional no 19, que transferiu grande parte da reforma do Estado para o âmbito constitucional, e por lá ficando, sem uma implementação efetiva em vários de seus pontos, tal como veremos mais abaixo. Logo em 1999, no início do segundo governo de FHC, o MARE foi extinto, sendo sua estrutura organizacional incorporada pela Secretaria de Gestão (SEGES), alocada no Ministério do Planejamento, Orçamento e Gestão (MPOG). Esse novo arranjo da reforma no interior da administração pública federal colocou uma série de problemas para a coordenação dos esforços. Para Martins (2002: 274), a liderança ministerial do MARE era forte e possibilitava que a reforma avançasse, porém, com a sua transferência para o MPOG a liderança ministerial não proporcionou a devida integração entre propostas reformistas e sua implementação.

No caso do MPOG, o problema da liderança ministerial é ainda mais crítico devido à quantidade de secretarias, ao fato de muitas delas terem sido justapostas a outras anteriores, em razão da extinção do MARE e ao fato de o MPOG ter a este vinculado, durante curto período de tempo uma Secretaria de Estado com papel coordenador, redundante e altamente conflitivo com a Secretaria-Executiva. Em momento posterior, a Secretaria-Executiva adjunta do MPOG teve um papel integrador fundamental. Não obstante, a SEGES, herdeira da orientação da reforma institucional, outrora na Secretaria de Reforma do Estado/MARE, era considerada pela cúpula do MPOG um domínio extraministerial, isso dificultava muito o diálogo e a integração vertical e horizontal dentro do ministério (Martins, 2002: 274)

Ainda sobre as dificuldades de coordenação no interior da administração pública federal no período da reforma do Estado iniciada em 1995, o fato de existir fraturas entre "ministérios poderosos", que impunham suas perspectivas sobre os demais, e ministérios mais frágeis criava tensões permanentes na implementação de programas e diretrizes reformadoras. A extinção do MARE e sua transferência para o MPOG acentuaram em grande medida essas fraturas interministeriais, e tal como vimos mais acima, aumentou o grau de conflitos intraministeriais. A conclusão que Martins (2002: 276) chega é que quanto mais se ascende

administração pública. Podemos ver isso nos próprios nomes dos programas de reforma. No Reino Unido a reforma foi intitulada de "joined-up government", focando na melhoria de coordenação de serviços entre as agencias governamentais. A Austrália adotou a abordagem "whole-of-government", enquanto alguns países da América do Norte perseguiram a estratégia "no-wrong-door", visando reduzir os gaps de gestão. na hierarquia governamental mais a coordenação se mostra falha. $\mathrm{O}$ exemplo concreto dessa falta de coordenação se deu no descompasso entre a política de ajuste fiscal empreendida pelo governo FHC principalmente durante seu segundo mandato (1999-2002) e a política de reforma do Estado. Pelo planejamento do MARE e seu corpo técnico, a política de ajuste fiscal seria um meio para se chegar à reforma administrativa pretendida, na qual iria ocorrer o corte do gasto público por meio da privatização de ativos estatais e uma redução dos quadros da administração pública. Porém, a política de ajuste fiscal se mostrou central para o governo FHC, deixando a reforma administrativa para um segundo plano. Fato é que o núcleo do governo FHC não estava tão empenhado em implementar a reforma administrativa, deixando o MARE numa espécie de isolamento institucional, carecendo de cooperação da parte de outros ministérios.

Para Rezende (2004), não houve uma cooperação entre o MARE e os outros ministérios para implementar as diretrizes da reforma. A situação após 1999 só se agravou, com a extinção do MARE. Em entrevista a Rezende (2004: 73), Bresser Pereira afirmou que:

O problema na reforma administrativa é que o MARE quis negociar isoladamente com os ministérios. Não tivemos a cooperação que esperávamos, e isto foi um grande problema para a implementação. A persuasão foi a principal arma [...] 80\% é persuasão numa reforma sem o poder e autoridade para implementar, o que torna o processo muito mais longo. O MARE teve que gastar muito tempo e energia para convencer os ministérios e outras instituições para transformar-se em agências executivas ou organizações sociais. Isso foi muito desgastante. A grande questão responsável por tudo isso foi que não tivemos poder e autoridade suficiente para implementar as mudanças institucionais desejadas no papel do Estado.

A explicação de Bresser Pereira para o isolamento do MARE no governo FHC é, a nosso ver, equivocada. O que houve foi uma ênfase do governo na agenda fiscal que deixou outras áreas, tal como a reforma do Estado do MARE, numa espécie de compasso de espera eterno. A centralidade da disciplina fiscal nos governos da segunda metade da década de 1990 no Brasil foi uma das características mais marcantes, resvalando em várias áreas da administração pública. Segundo Loureiro (2001: 89), foi a agenda fiscal do governo FHC que deu coesão à sua gestão, pois: 
Além dos superávits primários alcançados desde 1999, não só pelo governo federal, mas também pelos [entes da federação] subnacionais, as realizações do governo na área fiscal envolvem a privatização ou liquidação da maioria de bancos estaduais, a renegociação das dívidas dos governos subnacionais, a aprovação da Lei de Responsabilidade Fiscal e de regras mais rigorosas para o endividamento público no país.

Todos esses instrumentos forneceram grande capacidade de coordenação por parte do Ministério da Fazenda, encabeçado por Pedro Malan. O Ministério da Fazenda foi, na verdade, o superministério do governo FHC, coordenando ${ }^{15}$ os outros entes da administração pública federal, pautado sempre pela questão fiscal, que deu o norte de grande parte das políticas gestadas e implementadas no período (Loureiro e Abrucio, 1999). A capacidade de coordenação da administração pública federal durante os governos de FHC mostrou-se muito precária, tendo a sua ênfase dirigida à questão fiscal, mais do que uma reforma ampla de instituições e organizações de órgãos componentes da administração federal. Enquanto o MARE foi funcional para o projeto econômico-político neoliberal dos governos FHC ele teve apoio de outros ministérios, principalmente na liquidação de ativos públicos. Passada a avalanche privatizadora o que se viu foi um alijamento do núcleo "técnico" da reforma do Estado dos meios para concretizar o PDRE. Mais uma reforma que não se completou no país.

\section{Conclusão}

Trabalhamos neste artigo a coordenação administrativa no interior da administração pública federal em seus momentos críticos, ou seja, em momentos de reformas administrativas importantes. A nossa primeira hipótese era a de que houve uma continuidade no padrão institucional das reformas administrativas em centralizar a coordenação da administração pública em algum ministério ou órgão criado para esse fim específico. $\mathrm{O}$ exame de cada uma dessas reformas nos permite analisar uma série de instituições criadas para a centralização e coordenação de funções entre os entes da administração federal. O DASP na década de 1930, o Ministério do Planejamento e Coordenação Geral e posteriormente a SEPLAN durante o regime militar.

\footnotetext{
${ }^{15}$ Aqui podemos perceber uma coordenação de cariz horizontal, pois se pautava entre órgãos inseridos no mesmo nível da estrutura hierárquica, embora a coordenação de agências reguladoras e empresas estatais seja marcadamente vertical.
}

A década de 1990 é marcada pelo MARE, ministério criado para coordenar a reforma administrativa e a função dos outros entes da administração pública, solapado em grande medida pelo Ministério da Fazenda, que foi o real coordenador da administração pública do período.

Nossa segunda hipótese era de que cada um desses órgãos criados durante as reformas administrativas ou mesmo na disputa com outras instituições esteve fortemente condicionado pelas decisões políticas do executivo federal, nos casos analisados o DASP servindo a propósitos de agenda bem estabelecidos pelo executivo federal, com ênfase na presidência da república, assim como a SEPLAN. Já, durante o governo FHC o Ministério da Fazenda, acabou tomando a frente do MARE, limitando o seu escopo de coordenação. A observação das diretrizes e disputas permite vincular a subordinação desses órgãos de coordenação diretamente à presidência, o que não é nenhuma novidade, pois o mínimo que se espera de uma instituição coordenadora é que obedeça a um projeto minimamente estabelecido.

O momento de cada reforma administrativa estava inserido num contexto político, econômico e social muito específico, que nós pouco analisamos aqui, mas que fornece pistas interessantes para se pensar a repercussão de disputas sociais no interior das instituições, sem cair num viés de análise societalista. Esses momentos de reforma, caracterizados por nós como critical junctures, trouxeram importantes inovações ao desenho organizacional e ao funcionamento da administração pública federal, repercutindo ao longo do tempo e influenciando outras reformas. As reformas administrativas passaram por períodos de ênfase desenvolvimentista, tanto no plano institucional quanto no econômico, principalmente na década de 1930, até mesmo períodos de alijamento de setores importantes do Estado, tal como na reforma de 1995, influenciada pelo projeto político neoliberal.

Mesmo com as variações nas correlações de força entre grupos ocupantes do governo é que parece existir um padrão de continuidade institucional entre as reformas administrativas, principalmente no plano da coordenação. Em todos os casos uma agência ou uma espécie de superministério ficou encarregado de centralizar e coordenar os outros entes da administração pública. E essas agências ou superministérios sempre ficam sujeitos a um grande grau de conflito com outras instituições, no próprio processo de competição entre burocracias de diferentes órgãos da administração federal. 


\section{Referências}

Abrucio, Luiz. 2007. Trajetória recente da gestão pública brasileira: um balanço crítico e a renovação da agenda de reformas. Revista de Administração Pública. 41: 67-86. http://dx.doi.org/10.1590/ S0034-76122007000700005

Bouckaert, Geert; Peters, B. Guy e Verhoest, Koen. 2010. The Coordination of Public Sector Organizations: Shifting Patterns of Public Management. London. New York: Palgrave Macmillan.

Brasil. 1936. Lei 284, de 28 de outubro de 1936. Reajusta os quadros e os vencimentos do funcionalismo publico civil da União e estabelece diversas providencias. Diário Oficial da República Federativa do Brasil, Brasília, DF, out. Disponível em: <http://www2. camara.leg.br/legin/fed/lei/1930-1939/lei-284-28outubro-1936-503510-publicacaooriginal-1-pl.html>.

Brasil. 1937. Constituição dos Estados Unidos do Brasil de 1937. Disponível em: <://www.planalto.gov.br/ ccivil_03/constituicao/constituicao37.htm>

Brasil. 1938. Decreto-Lei n ${ }^{\circ}$ 579, de 30 de julho de 1938. Organiza o Departamento Administrativo do Serviço Público, reorganiza as Comissões de Eficiência dos Ministérios e dá outras providências. Diário Oficial da República Federativa do Brasil, Brasília, DF, jul. Disponível em: <http://www2.camara.leg.br/legin/ fed/declei/1930-1939/decreto-lei-579-30-julho-1938350919-publicacaooriginal-126972-pe.html>.

Brasil. 1967. Decreto-lei no 200, de 25 de fevereiro de 1967. Dispõe sôbre a organização da Administração Federal, estabelece diretrizes para a Reforma Administrativa e dá outras providências. Diário Oficial da República Federativa do Brasil, Brasília, DF, fev. Disponível em: <http://www.planalto.gov.br/ ccivil_03/decreto-lei/del0200.htm>.

Brasil. 1995. Plano diretor da reforma do aparelho do Estado. Brasília: Câmara da Reforma do Estado.

Bresser Pereira, Luiz Carlos. 1998. Reforma do Estado para a Cidadania: A Reforma Gerencial Brasileira na Perspectiva Internacional. Brasília/São Paulo: ENAP/Editora 34.

Codato, Adriano Nervo. 2008. Elites e Instituições no Brasil: uma Análise Contextual do Estado Novo. Tese de Doutorado. Universidade Estadual de Campinas. PMid:18813601.

Costa, Valeriano Mendes Ferreira. 2002. A Dinâmica Institucional da Reforma do Estado: Um Balanço o Período FHC. In. F. L. Abrucio e M. R. Loureiro (orgs.), O Estado numa era de reformas: os anos FHC. Brasília: Ministério do Planejamento/Pnud/OCDE.

Fausto, Bóris. 1972. Pequenos Ensaios de História da República: 1889-1945. Cadernos CEBRAP, 10.

Graham, Lawrence. 1968. Civil Service Reform in Brazil. Principles versus Practice. Austin, London: University of Texas Press
Geddes, Barbara. 1994. Politician's Dilemma: Building State Capacity in Latin America. Berkeley and London: University of California Press.

Lambert, Francis. 1968. Trends in Administrative Reform in Brazil. Latin American Studies, I(2): 167-188.

Loureiro, Maria Rita e Abrucio, Fernando Luiz. 1999. Política e burocracia no presidencialismo brasileiro: o papel do Ministério da Fazenda no primeiro governo Fernando Henrique Cardoso. Revista Brasileira de Ciências Sociais. 14(14): 69-89. http://dx.doi. org/10.1590/S0102-69091999000300005

Loureiro, Maria Rita. 2001. Instituições, Política e Ajuste Fiscal: O Brasil em perspectiva comparada. Revista Brasileira de Ciências Sociais.16(47): 75-96. http:// dx.doi.org/10.1590/S0102-69092001000300005

Martins, Luciano. 1985. Estado Capitalista e Burocracia no Brasil pós 64. Rio de Janeiro: Paz e Terra.

Martins, Humberto Falcão. 2002. Reforma do Estado E coordenação Governamental: as Trajetória das Políticas de Gestão Pública na Era FHC. In. F. L. Abrucio; M. R. Loureiro (Orgs.). O Estado numa era de reformas: os anos FHC. Brasília: Ministério do Planejamento/Pnud/OCDE.

Nogueira, Marco Aurélio. 1998. As Possibilidades da Política: Ideias para a Reforma Democrática do Estado. São Paulo: Paz e Terra.

Nunes, Edson. 1997. A Gramática Política do Brasil: Clientelismo e Insulamento Burocrático. Rio de Janeiro: ENAP/Zahar.

Pierson, Paul. 2004. Politics in Time: History, Institutions, and Social Analysis. Princeton: Princeton University Press.

Pollitt, Christopher. 1990. The New Managerialism and The Public Services: the Anglo American Experience. Oxford: Basil Blackwell.

Ramos, Guerreiro. 1983. Administração e Contexto Brasileiro: Esboço de uma Teoria Geral da Administração. Rio de Janeiro: Editora FGV.

Rezende, Flávio. 2004. Por Que Falham as reformas Administrativas? Rio de Janeiro: Editora FGV.

Siegel, Gilbert. 1966. The Strategy of Public Administration Reform: The Case of Brazil. Public Administration Review. 26(1): 45-55. http://dx.doi. org/10.2307/973929

Skocpol, Theda. 1985. Bringing the State Back In: Strategies of Analysis in Current Research. In. P. Evans, D. Rueschemeyer e T. Skocpol (eds.), Bringing the State Back In. Cambridge: Cambridge Press University. http://dx.doi.org/10.1017/CBO9780511628283.002

Thelen, Kathleen. 1999. Historical institutionalism in comparative politics. Annual Reviews of Political Science, 2: 369-404. http://dx.doi.org/10.1146/ annurev.polisci.2.1.369 